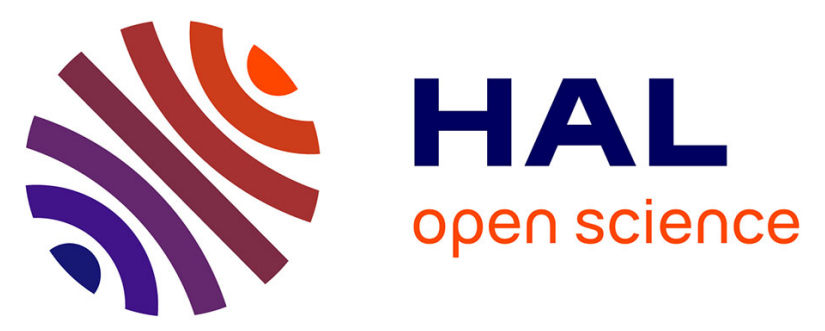

\title{
Multi-scale structural characterizations of fatty acid tubes with temperature tuneable diameter in bulk and at the air/water interface
}

Anne Laure Fameau, Fabrice Cousin, François Boué, F. Nallet, L. Navailles, Frédéric Ott, B. Novales, Jean Paul Douliez

\section{To cite this version:}

Anne Laure Fameau, Fabrice Cousin, François Boué, F. Nallet, L. Navailles, et al.. Multi-scale structural characterizations of fatty acid tubes with temperature tuneable diameter in bulk and at the air/water interface. Neutron News, 2012, 23 (2), pp.25-28. 10.1080/10448632.2012.673438 . hal00708265

\section{HAL Id: hal-00708265 \\ https://hal.science/hal-00708265}

Submitted on 10 Oct 2017

HAL is a multi-disciplinary open access archive for the deposit and dissemination of scientific research documents, whether they are published or not. The documents may come from teaching and research institutions in France or abroad, or from public or private research centers.
L'archive ouverte pluridisciplinaire HAL, est destinée au dépôt et à la diffusion de documents scientifiques de niveau recherche, publiés ou non, émanant des établissements d'enseignement et de recherche français ou étrangers, des laboratoires publics ou privés. 


\title{
Multi-scale structural characterizations of fatty acid tubes with temperature tuneable diameter in bulk and at the air/water interface
}

\author{
A. L. Fameau ${ }^{1,2}$, F. Cousin ${ }^{2}$, F. Boue ${ }^{2}$, F. Nallet $^{3}$, L. Navailles $^{3}$, \\ F. Otт ${ }^{2}$, B. Novales ${ }^{1}$, and J. P. Douliez ${ }^{1}$ \\ ${ }^{1}$ Biopolymères Interactions Assemblages, INRA, rue de la Géraudière, 44316 Nantes, France \\ ${ }^{2}$ Laboratoire Léon Brillouin, CEA Saclay, 91191 Gif sur Yvette Cedex, France \\ ${ }^{3}$ Centre de recherche Paul-Pascal - CNRS, 115 avenue du Docteur- Schweitzer, 33600 Pessac, France
}

\section{Towards a new class of green surfactants}

The use of agricultural resources for industrial purposes will undoubtedly be one of the major challenges of the $21^{\text {st }}$ century, either from the energetic point of view by the progressive replacement of fossil fuels or with respect to non-energy uses by making available new organic "biosynthons" to the chemicals industry. In such a context, we demonstrate here the strong potential of dispersions of saturated fatty acids and their hydroxylated derivatives, extracted from biological compounds of plant origin, as a new class of green surfactants.

We choose as fatty acid the 12-hydroxystearic acid (12HSA), derived from the castor oil, as it is a sustainable material, available in large amounts and at low cost. When dispersed in aqueous solution with ethanolamine as counterion, the 12-HSA spontaneously self-assemble in tubes of around $10 \mu \mathrm{m}$ length and $600 \mathrm{~nm}$ diameter [1-2]. Interestingly, such tubes exhibit a remarkable thermal behavior since the outer tube diameter can be increased by a factor $\sim 10$ in a span of a few degrees (Figure 1). The diameter of the tubes has a rather constant value of around $0.6 \mu \mathrm{m}$ from $20^{\circ} \mathrm{C}$ to $47^{\circ} \mathrm{C}$, a temperature at which it starts to increase to reach a maximum value of $5 \mu \mathrm{m}$ at $50^{\circ} \mathrm{C}$ [3]. Then, it decreases again upon a further increase of temperature. Finally, at $70^{\circ} \mathrm{C}$ the solution becomes isotropic because tubes melt into micelles. Besides their astonishing thermal properties, those solutions of tubes exhibit outstanding foam stability in comparison with common surfactants [4].

Until now, the mechanisms that drive the tuneable variation of the diameter with temperature are not yet described. The origin of the outstanding foam stability is still also not understood. Answering these questions necessitate a clear structural description of the tubes at local scale as a function of temperature, either in bulk solution and either at the air/ water interface to determine if the tubular structures remain stable at a water/hydrophobic interface. We have thus coupled SANS and neutron reflectivity to perform a full structural characterization of the system in both geometries.
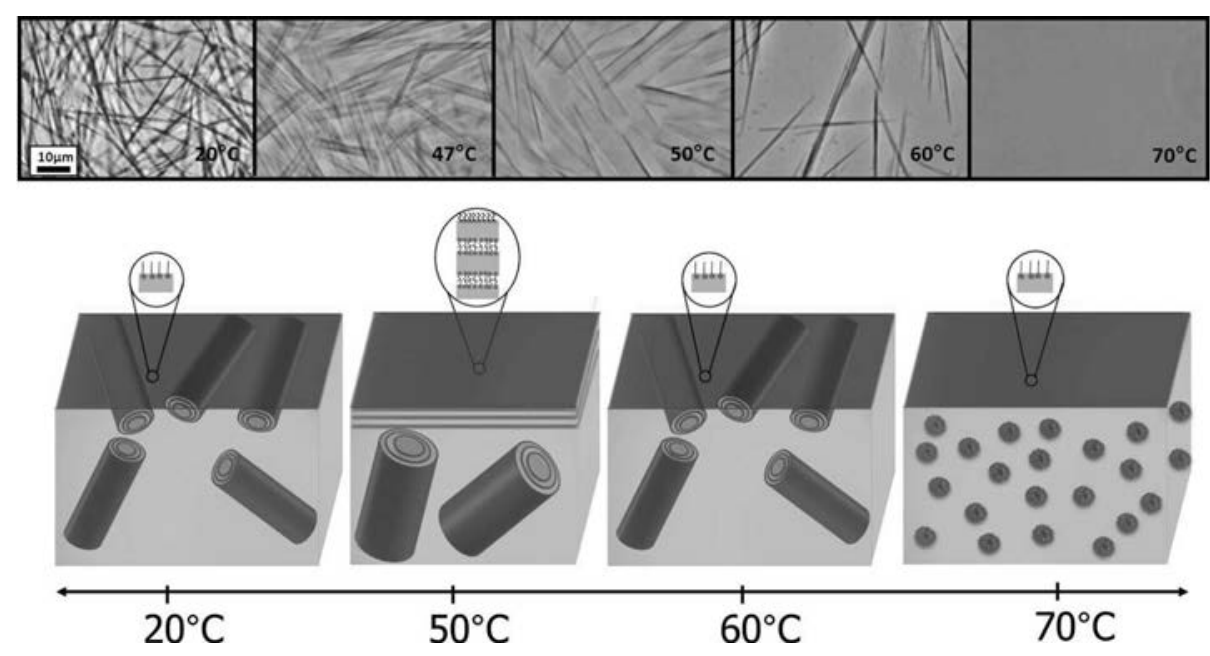

Figure 1. Pictures of 12-HSA tubes. Schematic representation of the structural behavior of tubes in bulk and at the air/water interface as a function of the temperature. 

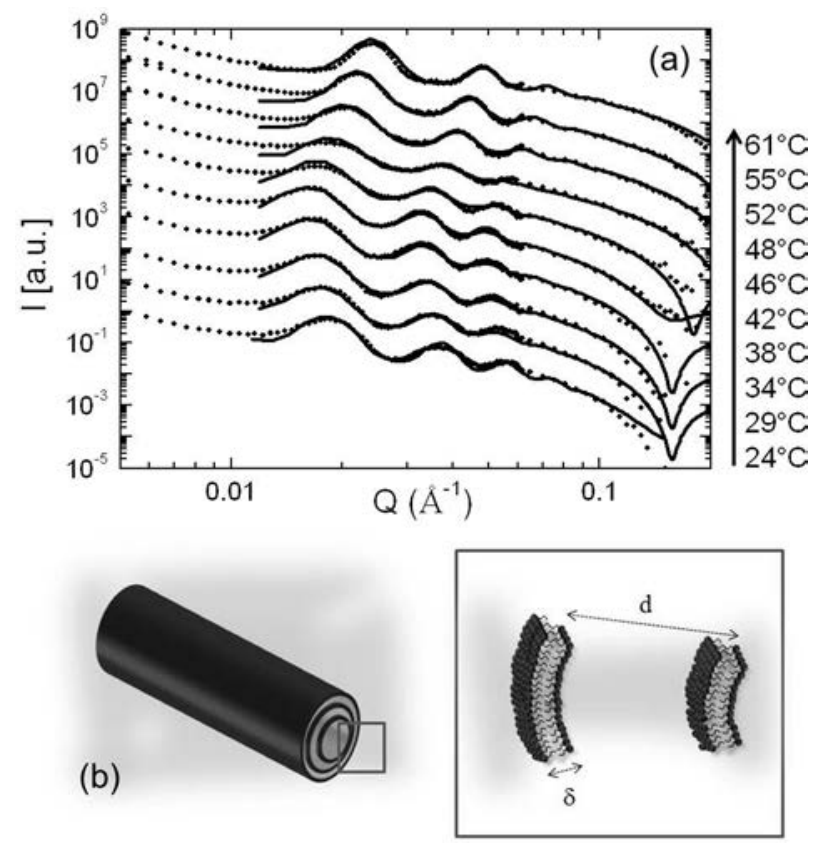

Figure 2. (a) SANS intensity profile for a tube solution as a function of the temperature. (b) Schematic representation of the multilayer tubes (d, interlayer spacing) ( $\delta$, bilayer thickness).

\section{Bulk study}

In order to probe the structural variation of the fatty acids tubes in bulk solution with temperature, we performed SANS experiments between $24^{\circ} \mathrm{C}$ and $61^{\circ} \mathrm{C}$. At $24^{\circ} \mathrm{C}$, the scattered intensity exhibits well defined features with three sharp marked peaks (see Figure 2a). The peaks are located at $\mathrm{Q}_{0}=0.018$, 0.036 and $0.054 \AA^{-1}$ thus exactly in a ratio of $1: 2: 3$. We therefore describe them as Bragg peaks arising from the $1 \mathrm{D}$ periodic stacking of lipid bilayers separated by water. The tubes are formed by periodically stacked concentric layers (Figure 2b). The interlayer spacing (i.e. the distance corresponding to one lipid bilayer and a water layer) can be directly determined from $2 \pi / Q_{0}$. It is $325 \AA$ at $24^{\circ} \mathrm{C}$. As the radius of curvature of the tube walls is always much larger than the spatial scale probed in the SANS experiment, it is possible to describe the experimental scattering curve with a simple model of planar membranes of well-defined thickness $\delta$ being stacked with a period $d$. In the model, we took into account the thermally induced elastic fluctuations in the lamellar stack and the finite resolution of the SANS spectrometer [5]. Thus, the modeling of the SANS spectrum on the whole Q range allowed an estimation of two relevant quantities of the system: the Caille parameter $\eta$ (accounting for the thermal fluctuations), which is essentially determined from the shape of the Bragg peak in the low Q region, and the bilayer thickness $\delta$ in the large $\mathrm{Q}$ region. It yields a value of $41 \AA$ for the bilayer thickness and 0.045 for the Caillé parameter at $24^{\circ} \mathrm{C}$. Since the stacking period is large, such a small value of the Caillé parameter suggests very rigid bilayers (curvature modulus on the order of $50_{\mathrm{kB}} \mathrm{T}$ ) in association with strong interactions in the lamellar stack. The value obtained for the membrane thickness corresponds to almost twice the length of the stearic chain in its extended conformation which is $21 \AA$. The SANS data are then consistent with fatty acids organized in bilayers in their gel state $L \beta$, which is compatible with the above mentioned high membrane rigidity.

The evolution of the three main parameters extracted from the SANS scattering curve (interlayer spacing $d$, bilayer thickness $\delta$ and the Caillé parameter $\eta$ ) were then determined when increasing temperature. The experimental scattering spectra are represented in Figure 2a. The interlayer spacing strongly changes with temperature (Figure 3a): it progressively increases slightly from $34 \mathrm{~nm}$ at $24^{\circ} \mathrm{C}$ to reach a maximum of $38 \mathrm{~nm}$ at $45^{\circ} \mathrm{C}$ and then drops down to $27 \mathrm{~nm}$ at $61^{\circ} \mathrm{C}$. It appears that the temperature at which the interlayer spacing drops $\left(45^{\circ} \mathrm{C}\right)$ corresponds roughly to the one at which the tube diameter starts to increase $\left(47^{\circ} \mathrm{C}\right)$. Thus, there is no direct correlation between the increase of the tube diameter at large scale and the variations of the interlayer spacing at local scale.

The evolution of the bilayer thickness as a function of the temperature enabled to determine precisely the gel-fluid $\mathrm{L} \beta \mathrm{L} \alpha$ transition temperature. From $24^{\circ} \mathrm{C}$ to $45^{\circ} \mathrm{C}$, the model yielded a constant value of the bilayer thickness $\delta$ of around $41 \AA$. The bilayers are embedded in the gel state $\mathrm{L} \beta$ for this range of
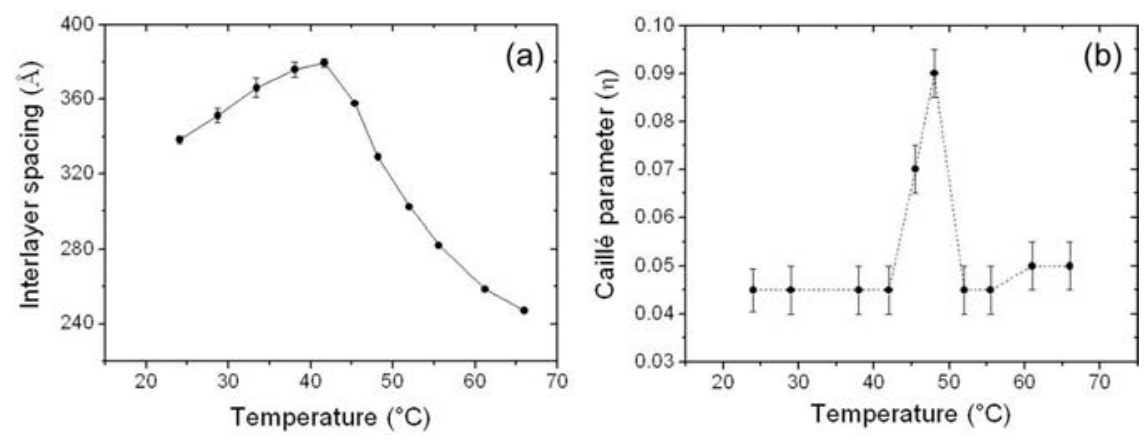

Figure 3. (a) Evolution of the interlayer spacing and (b) the Caillé parameter as a function of the temperature. 
temperatures. However, above $47^{\circ} \mathrm{C}$ the bilayers thickness decreased drastically down to a value of $27 \AA$, a thickness markedly lower, indicating that the fatty acids are in the fluid phase (L $\beta)$. This $\mathrm{L} \beta \mathrm{L} \alpha$ transition of the bilayers occurs exactly at the temperature at which the tube's diameter starts to increase. The increase of the tube diameter at large scale is then associated with the phase transition of the bilayers.

Finally, the evolution of the Caille parameter as a function of the temperature enabled us to evidence the link between the rigidity of the membranes and the outer diameter of the tubes (Figure $3 \mathrm{~b}$ ). From $24^{\circ} \mathrm{C}$ to $45^{\circ} \mathrm{C}$, the model yielded a value of the Caillé parameter constant around 0.0045 . However, at $47^{\circ} \mathrm{C}$, the temperature at which the tube diameter starts to increase, the Caillé parameter increased by more than a factor of two $(\eta=$ 0.009). Then, above $50^{\circ} \mathrm{C}$, it decreased back to reach the same value as obtained from $24^{\circ} \mathrm{C}$ to $45^{\circ} \mathrm{C}$. It clearly shows that the elastic properties of the bilayer stack are strongly modified at the temperature at which the tube diameter increases, as the stack becomes much softer in this temperature range [6].

\section{Interfacial study}

To determine the structural behavior of those tubes at the air/water interface, we used Specular Neutron Reflectivity (SNR). In Figure 4a, we present the SNR measurements performed at the interface on solutions of fatty acid tubes at $20^{\circ} \mathrm{C}$, which show regular interference fringes on the low Q-range. This shows that there is a layer of several hundred of Angstroms of fatty acid materials at the interface. A calculation of the thickness of the fatty chain layer from the d-spacing of the interferences fringes $(\mathrm{d} \sim 2 \mathrm{C} / \mathrm{Q})$ provides a thickness of $\sim$ $300 \AA$ A. In order to model our SNR data, we started testing simple models of fatty acid arrangements at the air/water interface already described in the literature: (1) a single monolayer of fatty acids and (2) lamellar phases stacked parallel to the interface [7]. These models largely fail to describe the experimental data. Then, we developed a model considering that the tubes are adsorbed at the interface on a fatty acid monolayer (Figure 4b). In such a model, we consider tubes with the same geometrical parameters as for tubes in bulk solution [8]. This model enabled to obtain a rather good description of the SNR experimental curve, in particular the damped shape of the fringes, showing that tubes are adsorbed at the interface.

We then studied the evolution of the SNR experimental scattering curve with temperature. The interlayer spacing of

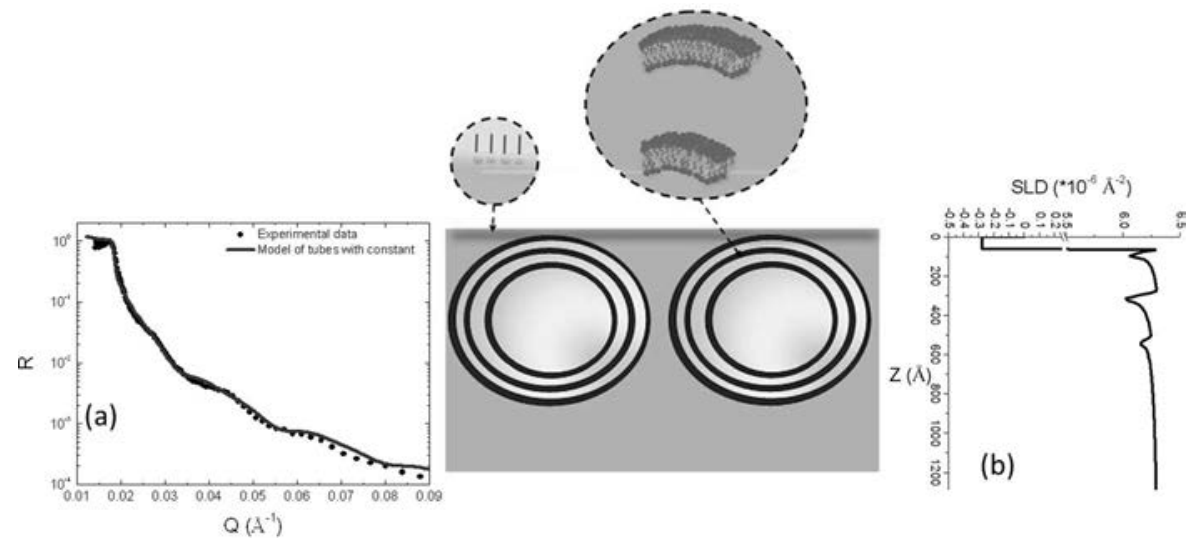

Figure 4. (a) Comparison of the SNR results of a tubes solution at $20^{\circ} \mathrm{C}$ with the model of tubes adsorbed at the interface. (b) Description of the model of tubes adsorbed at the interface with the corresponding SLD profile. 

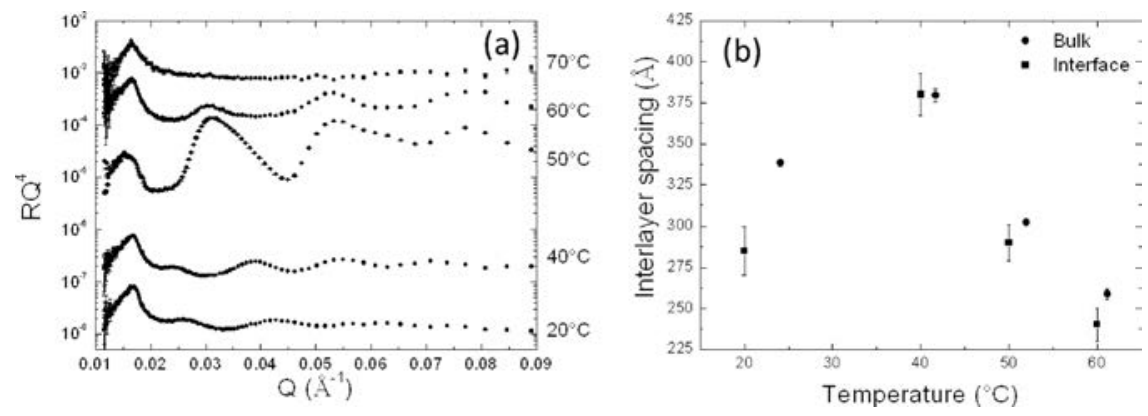

Figure 5. (a) Evolution with temperature of the SNR curve. (b) Comparison between the evolution with temperature of the interlayer spacing of tubes either in bulk or at the air/water interface.

tubes adsorbed at the interface was determined from the Q-position of the interferences fringes (Figure $5 \mathrm{a}$ ). At $40^{\circ} \mathrm{C}$, the SNR curve has a very similar shape as the one obtained at $20^{\circ} \mathrm{C}$. The fringes are slightly shifted towards low $\mathrm{Q}$, indicating an increase of the interlayer spacing $d$, similarly to what was observed for the tubes in bulk solution.

At $50^{\circ} \mathrm{C}$, the structural behavior completely changes. It corresponds to the temperature for which the tube diameter increases drastically in bulk. One observes strong marked fringes. The experimental curve corresponds to flat stacked bilayers at the interface. Since the tube diameter at the interface increases at $50^{\circ} \mathrm{C}$, it is likely that the tubes have coalesced, which induced unfolding, and then form an ordered lamellar phase stacked below the interface.

At $60^{\circ} \mathrm{C}$, a temperature at which the tube diameter has decreased back to its initial value in bulk, at the interface a SNR curve exhibits the same features observed at $20^{\circ} \mathrm{C}$. Tubes are again adsorbed at the interface. The lamellar phases at the surface observed at $50^{\circ} \mathrm{C}$ have thus re-folded to again form tubes at the interface. The interlayer spacing $d$ at $60^{\circ} \mathrm{C}$ for tubes at the interface has decreased compared to the one at $20^{\circ} \mathrm{C}$, similarly as observed for the tubes in bulk solution. Finally, at $70^{\circ} \mathrm{C}$ the fringes completely vanish. At this temperature, tubes melt into micelles in bulk. The disappearance of the fringes comes thus from the melting of the tubes, letting just a single monolayer of fatty acids at the air/water interface. We have also checked that all structural transitions with temperature at the interface are quasi-completely reversible.

Remarkably, the interlayer spacing $d$ has exactly the same values in bulk and at the air/water interface (Figure 5b). It follows the same trends in both geometries confirming from a quantitative point of view the link between surface and bulk, suggesting that the surface structure is driven by the bulk structure.

\section{Conclusion}

Although there still remain some points to clarify for a full understanding of the thermal behavior of the 12-HSA tubes, we demonstrated that the increase of the tube diameter is linked to the phase transition of the bilayers and to a softening of the bilayers stack by coupling SANS and microscopy to probe the systems at different length scales. Moreover, we have shown by SNR that tubes adsorb at the air/water interface with almost the same swelling/deswelling dependence with temperature as in bulk (see Figure 1). Remarkably, the structural transitions at the interface are reversible similarly than in bulk. The self-assemblies of those tubes with temperature-tuneable surface properties that we have highlighted here have a strong potential in the design of responsive foams and emulsions $-\mathrm{a}$ field of growing interest.

\section{References}

1. J. P. Douliez, C. Gaillard, L. Navailles, and F. Nallet, Langmuir 22, 2942-2945 (2006).

2. A. L. Fameau, B. Houinsou, B. Novales, L. Navailles, F. Nallet, and J. P. Douliez, J. Colloid Interface Sci. 341, 38-47 (2010).

3. J. P. Douliez, B. Pontoire, and C. Gaillard, Chemphyschem 7, 2071-2073 (2006).

4. A. L. Fameau, A. Saint-Jalmes, F. Cousin, B. Houssou, B. Novales, L. Navailles, F. Nallet, C. Gaillard, F. Boué, and J. P. Douliez, Angew. Chem. Int. Ed 50, 8264-8269 (2011).

5. F. Nallet, R. Laversanne, and D. Roux, Journal de Physique II 3, 487-502 (1993).

6. A. L. Fameau, F. Cousin, L. Navailles, F. Nallet, F. Boué, and J. P. Douliez, J. Phys. Chem. B 115, 9033-9039 (2011).

7. D. J. McGillivray, R. K. Thomas, A. R. Rennie, J. Penfold, and D. S. Sivia, Langmuir 19, 7719-7726 (2003).

8. A. L. Fameau, F. Cousin, L. Navailles, F. Nallet, F. Boué, and J. P. Douliez, J. Colloid Interface Sci. 362, 397-405 (2011). 